\title{
Applying Verbal Decision Analysis to Task Allocation in Distributed Development of Software
}

\author{
Marum Simão Filho \\ Graduate Program in Applied Computer Science \\ University of Fortaleza / 7 de Setembro College \\ Fortaleza, Brazil \\ marum@unifor.br
}

\author{
Plácido R. Pinheiro, Adriano B. Albuquerque \\ Graduate Program in Applied Computer Science \\ University of Fortaleza \\ Fortaleza, Brazil \\ \{placido, adrianoba\}@unifor.br
}

\begin{abstract}
The management of distributed software development projects presents many challenges. One of them happens right at the start of the project and consists of the allocation of tasks between remote teams. When allocating a task to a site, the project manager takes into account several factors such as technical knowledge of staff and proximity to the client. The project manager usually takes this decision in a subjective way. The verbal decision analysis is an approach based on solving problems through multi-criteria qualitative analysis, which means it considers the analysis of subjective criteria. This paper describes the application of verbal decision analysis methodologies ORCLASS and ZAPROS III-i to classify and rank the most relevant factors that the project managers should take into account when allocating tasks in projects of distributed development of software.
\end{abstract}

Keywords - Distributed Development of Software, Task Allocation, Verbal Decision Analysis, ORCLASS, ZAPROS III-i.

\section{INTRODUCTION}

The Distributed Development of Software (DDS) is a reality more and more present in modern companies. The perspective to expand the workforce capacity, the conquest of new markets and the cost reduction possibility are some of the reasons that make software development companies adopt distributed development [27]. On the other hand, the distribution brings many challenges, such as language and time zone differences and increased complexity of coordinating and controlling the project [25]. In this context, the allocation of tasks is an even more critical activity for project planning because of the distribution [24]. The distribution of tasks to remote teams can be seen as a fundamental activity for the success of a distributed project. However, this activity is still a major challenge in global software development due to limited understanding of the factors that influence task allocation decisions [8].

Deciding which task we should allocate for each team is typically a decision-making problem. Routinely, the project manager makes this decision based on their experience and knowledge about the project and the teams involved. We mean that a high degree of subjectivity is present in the decisionmaking process. This is an appropriate setting for Verbal decision analysis (VDA), which consist of an approach based on multicriteria problem solving through its qualitative analysis [17], i.e., VDA methods take into consideration the criteria's subjectivity.

DOI reference number: 10.18293/SEKE2016-181
This paper describes the application of a hybrid methodology using VDA methods to classify and rank order the most relevant factors to be considered by project managers when allocating tasks in projects of distributed development of software. Firstly, expert interviews were conducted to identify the criteria and the criteria values. Then, a questionnaire was applied to a group of project managers to characterize each factor through the criteria and criteria values. Next, the ORCLASS method was applied to divide the factors into preference groups. Finally, the ZAPROS III-i was then applied to rank order the preferable factors.

The rest of the paper is organized as follows: Section II shortly deals with issues involving task allocation in distributed development of software. Section III provides a brief description of the verbal decision analysis methods ORCLASS and ZAPROS III-i. Section IV describes the application of the hybrid methodology using ORCLASS and ZAPROS III-i. Section V presents the results of our work. Finally, in Section VI, we provide the conclusions and suggestions for further work.

\section{TASK ALLOCATION IN DDS}

The allocation of tasks is a critical activity for any kind of project, especially in a distributed scenario. Most of the time, few factors drive the allocation of tasks, such as hand labor costs. Risks and other relevant factors such as the workforce skills, innovation potential of different regions, or cultural factors are often insufficiently recognized [12].

Many studies about the tasks allocation in DDS have been carried out along the years aiming at mapping this topic and its features. Lamersdorf et al. [12] developed an analysis of the existing approaches to distribution of duties. The analysis was comprehensive and involved procedures for the distributed development, distributed generation, and distributed systems areas. Lamersdorf et al. [13] conducted a survey on the state of practice in DDS in which they investigated the criteria that influence task allocation decisions. Lamersdorf and Münch [11] presented TAMRI (Task Allocation based on Multiple cRIteria), a model based on multiple criteria and influencing factors to support the systematic decision of task allocation in distributed development projects.

Ruano-Mayoral et al. [31] presented a methodological framework to allocate work packages among participants in global software development projects. Marques et al. [25] performed a systematic mapping, which enabled us to identify models that propose to solve the problems of allocation of 
tasks in DDS projects. They intended to propose a combinatorial optimization-based model involving classical task scheduling problems. Marques et al. [24] also performed a tertiary review applying the systematic review method on systematic reviews that address the DDS issues.

Galviña and Šmite [9] provided an extensive literature review for understanding the industrial practice of software development processes and concluded that the evidence of how these projects are organized is scarce. Babar and Zahedi [3] presented a literature review considering the studies published in the International Conference in Global Software Engineering (ICGSE) between 2007 and 2011. It was found that the vast majority of the evaluated studies were in software development governance and its sub-categories, and much of the work had focused on the human aspects of the GSD rather than technical aspects.

Almeida et al. [1] presented a multi-criteria decision model for planning and fine-tuning such project plans: Multi-criteria Decision Analysis (MCDA). The model was developed using cognitive mapping and MACBETH (Measuring Attractiveness by a Categorical Based Evaluation Technique) [4]. In [2], Almeida et al. applied (MCDA) on the choice of DDS Scrum project plans that have a better chance of success.

Simão Filho et al. [32] conducted a quasi-systematic review of studies of task allocation in DDS projects that incorporate agile practices. The study brought together a number of other works, allowing the establishment of the many factors that influence the allocation of tasks in DDS. These factors are very important for this work and will be mentioned later.

\section{VERBAL DECISION ANALYSIS}

Decision-making is an activity that is part of people's and organizations' lives. In most problems, to make a decision, a situation is assessed against a set of characteristics or attributes, i.e., it involves the analysis of several factors, also called criteria. When a decision can generate a considerable impact, such as management decisions, and must take into account some factors, the use of methodologies to support the decisionmaking process is suggested, because choosing the inappropriate alternative can lead to waste of resources, time, and money, affecting the company.

The decision-making scenario that involves the analysis of alternatives from several viewpoints is called multi-criteria decision analysis and is supported by multicriteria methodologies [4]. These methodologies favor the generation of knowledge about the decision context, which helps raise the confidence of the decision maker [8 and 23].

The verbal decision analysis is an approach to solving multicriteria problems through qualitative analysis [15]. The VDA supports the decision-making process through the verbal representation of problems. Some examples of the application of VDA in real problems are given next. In [20], Machado et al. applied VDA to CMMI practices. In [26 and 40], the authors used VDA in digital TV applications. In [21], Machado applied a hybrid model of VDA in selecting project management approaches. In [37], Tamanini et al. proposed a VDA-based model to cashew chestnut industrialization process. In [5, 6, 7, 38 and 39], the authors developed studies applying VDA to the diagnosis of Alzheimer's disease. In [41], Tamanini and Pinheiro approached the incomparability problem on ZAPROS. In [30], Pinheiro et al. studied multicriteria on the learning process in software engineering.

According to [28], the traditional methods of VDA aimed at solving problems with a lot of alternatives and a limited number of criteria and criteria values, since they were designed for the construction of a general rule for the decision, regardless of which alternatives belonged to the real alternatives set. However, this characteristic has changed recently, and new methods that elicit the preferences based on the real alternatives to the problem have been proposed.

The VDA methodologies can be used for ordering or sorting the alternatives. Among the classification methods, we can mention ORCLASS, SAC, DIFCLASS, and CYCLE. Some sorting methods are PACOM, ARACE, and those from ZAPROS family (ZAPROS-LM, STEPZAPROS, ZAPROS III and III-i) [34]. Fig. 1 shows the VDA classification and ordering methods.

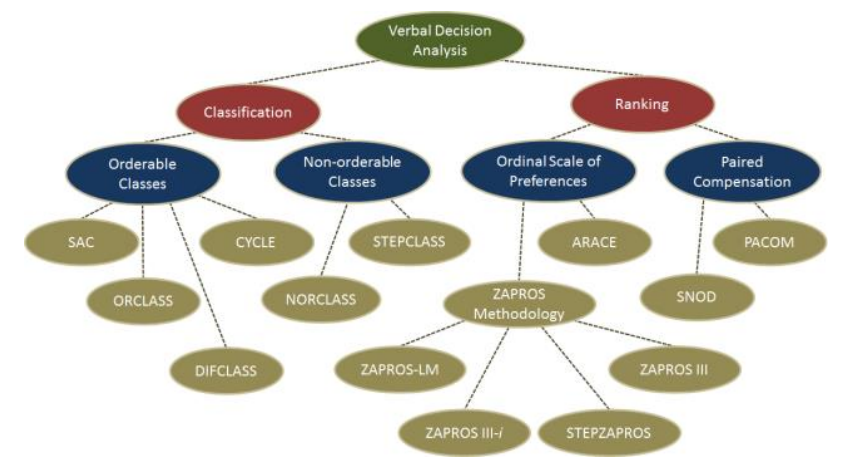

Fig. 1. VDA Methods for Classification and Ordering [34]

\section{A. The ORCLASS Method for Classification}

ORCLASS methodology aims at classifying the alternatives in a given set: the decision maker needs these alternatives to be categorized into a small number of decision classes or groups, usually two. The first group covers the most preferable alternatives, and the less preferable alternatives belong to the second one [17].

The flowchart with steps to apply the ORCLASS method was presented in [35]. In that scheme, the application of the ORCLASS method can be divided into three stages: Problem Formulation, Structuring of the Classification Rule and Analysis of the Information Obtained. In the first stage, the problem's formulation, the set of criteria, criteria values, and the decision groups are defined. The criteria values must be sorted in an ascending order of preference (from most to least preferable). In case of three criteria and three criteria values, we have the following criteria values for each criterion: A1, A2 and $\mathrm{A} 3$ (for criterion $\mathrm{A}$ ), B1, B2 and B3 (for criterion B), and $\mathrm{C} 1, \mathrm{C} 2$ and $\mathrm{C} 3$ (for criterion $\mathrm{C}$ ). $\mathrm{A} 1, \mathrm{~B} 1$ and $\mathrm{C} 1$ are the most preferable values, and $\mathrm{A} 3, \mathrm{~B} 3$ and $\mathrm{C} 3$ are the least preferable values for criteria $\mathrm{A}, \mathrm{B}$ and $\mathrm{C}$, respectively. In this case, possible alternatives are represented as $[\mathrm{A} 1, \mathrm{~B} 2, \mathrm{C} 3]$ and [A3, $\mathrm{B} 1, \mathrm{C} 2]$.

Then, the construction of the classification rule is carried out based on the decision maker's preferences. We use the 
same concepts presented in [17], based on which a classification task is presented as a set of boards. Each cell of the board is composed of a combination of values for each criterion defined for the problem, which represents a possible alternative to the problem [23]. It should be noted that the most preferable hypothetical alternative naturally belongs to the first group ([A1B1C1]) as long as the least preferable one belongs to the second group ([A3B3C3]).

To facilitate the decision-making process, Machado et al. developed a tool called ORCLASSWEB, and made it available for use over the Internet (http://www2.unifor.br/OrclassWeb) [22]. The ORCLASSWEB tool proposes to automate the comparison process of alternatives and to provide the decision maker a concrete result for the problem, according to ORCLASS definition. Other applications of the ORCLASS method can be found in [10, 19 and 23].

\section{B. The ZAPROS III-i Method for Rank Ordering}

The ZAPROS methodology aims at ranking multi-criteria alternatives in scenarios involving a rather small set of criteria and criteria values, and a great number of alternatives. It is structured in three stages: Problem Formulation, Elicitation of Preferences and Comparison of Alternatives.

In ZAPROS LM method, we carry out the elicitation of preferences by comparing vectors of alternatives [17]. The ZAPROS III method [14] is an evolution of the ZAPROS LM. There are modifications that make it more efficient and more accurate on inconsistencies. The subjectivity and the qualitative aspect of ZAPROS method can cause losses to the method's comparison capacity and make the incomparability cases between the alternatives unavoidable [16]. ZAPROS III-i introduces modifications in the comparison process of alternatives so that it could minimize or even eliminate the incomparability problem of the ZAPROS method [43].

The ZAPROS III-i method's flowchart to rank order a set of alternatives can be found in [35]. In the first stage, we obtain the relevant criteria and their values to the decision-making process. In the second stage, we generate the scale of preferences based on the decision maker's preference. In the last stage, we perform the comparison between the alternatives based on the decision maker's preferences. Trying to reduce the number of incomparability cases, we apply the same structure proposed in [14], but the comparison of pairs of the alternatives' substage was modified according to the one proposed in [29].

\section{THE HYBRID METHODOLOGY APPLICATION}

To classify and rank order the most important factors that project managers should consider when allocating tasks in projects of distributed development of software, we applied a hybrid methodology, which consists of five main steps, as follows:

A - Identification of the Influencing Factors;

B - Definition of the Criteria and Criteria values;

C - Definition of the Alternatives, Decision Groups, and Alternatives' Characterization;

D - The ORCLASS Method Application; and

E - The ZAPROS-III-i Method Application.
In the next subsections, we explain each of de steps.

\section{A. Identification of the Influencing Factors}

First, we conducted a literature research to identify the main influencing factors that should be considered when allocating tasks in projects of distributed development of software. Table 1 shows the factors found as a result of this research, and that worked as the alternatives to our decision problem [35].

\begin{tabular}{ll} 
TABLE 1. INFLUENCING FACTORS ON TASK ALLOCATION IN DDS PROJECTS \\
\hline ID & Alternatives \\
\hline Factor1 & Technical expertise \\
Factor2 & Expertise in business \\
Factor3 & Project manager maturity \\
Factor4 & Proximity to client \\
Factor5 & Low turnover rate \\
Factor6 & Availability \\
Factor7 & Site maturity \\
Factor8 & Personal trust \\
Factor9 & Time zone \\
Factor10 & Cultural similarities \\
Factor11 & Willingness at site \\
\hline
\end{tabular}

\section{B. Definition of the Criteria and Criteria values}

Next, we interviewed a group of 4 project management experts to define the criteria and the criteria values. This is the definition stage of the criteria. For each criterion, we established a scale of values associated with it [18, 19 and 40]. The criteria values were ordered from the most preferable value to the least preferable one. As result of this step, we got the list of criteria and criteria values for the problem of selecting the most important factors to be considered in task allocation in DDS projects, which is listed next [33]:

1. Criterion A: Facility for carrying out the task remotely.

- A1. It facilitates much: The implementation of the remote task is much easier if the factor is present.

- A2. It facilitates: The implementation of the remote task is easier if the factor is present.

- A3. Indifferent: The presence of the factor is indifferent to the implementation of the remote task.

2. Criterion B: Time for the project.

- B1. High gain: The presence of the factor can cause much reduction of the period referred to perform the task.

- B2. Moderate gain: The presence of the factor may cause some reduction of the time limit for performing the task.

- B3. No gain: The presence of the factor does not cause changes to the deadline to execute the task.

3. Criterion C: Cost for the project.

- $\mathrm{C} 1$. High gain: The presence of the factor can cause a lot of cost reduction expected to perform the task.

- C2. Moderate gain: The presence of the factor may cause some reduction of the time limit for performing the task.

- C3. No gain: The presence of factor induces no change compared to the estimated cost to perform the task.

\section{Definition of the Alternatives, Decision Groups, and} Alternatives' Characterization

We created a questionnaire to gather information and opinions about the factors that influence the allocation of tasks 
in DDS projects. We applied the questionnaire to the Web to a group of 20 project managers and consisted of two parts. The first part aimed to trace the respondents profile about his/her professional experience and education.

The second part of the questionnaire inquired the views of experts on the factors that influence the allocation of tasks in DDS projects. For our problem, we described such influencing factors as alternatives. Thus, in every question, the professional analyzed the influencing factors about a set of criteria and criteria values and selected what criterion value that best fitted the factor analyzed. An example of question is as follows:

1. Factor: Technical expertise - knowledge of the techniques, languages, frameworks, tools, APIs, etc. needed by the team to accomplish the task.

(a) Criterion A: Facility for carrying out the task remotely

( ) A1. It facilitates much. ( ) A2. It facilitates. ( ) A3. Indifferent.

(b) Criterion B: Time for the project

( ) B1. High gain. ( ) B2. Moderate gain. ( ) B3.No gain.

(c) Criterion $\mathrm{C}$ : Cost for the project

( ) B1. High gain. ( ) B2. Moderate gain. ( ) B3.No gain.

We did the same for the other ten factors. Then, we analyzed the responses to determine the criteria values representing the alternatives. For each influencing factor, we filled the final table based on the replies of the majority of professionals. We then selected the value of the criterion that had the greatest number of choices to represent the alternative. Table 2 summarizes the responses to the questionnaire, showing the sum of the answers and characterization of alternative according to the values of each criterion (represented in the "Final Vector" column). The bold numbers in gray cells in the table indicate the criteria values selected by most of the interviewed professionals to represent a certain factor.

TABLE 2. CHARACTERIZATION OF ALTERNATIVES [33]

\begin{tabular}{|c|c|c|c|c|c|c|c|c|c|c|}
\hline \multirow{2}{*}{$\begin{array}{l}\text { Criteria/ } \\
\text { alternatives }\end{array}$} & \multicolumn{3}{|c|}{$\begin{array}{l}\text { Facility for carrying } \\
\text { out the task remotely }\end{array}$} & \multicolumn{3}{|c|}{$\begin{array}{l}\text { Time for the } \\
\text { project }\end{array}$} & \multicolumn{3}{|c|}{$\begin{array}{l}\text { Cost for the } \\
\text { project }\end{array}$} & \multirow[b]{2}{*}{ Final vector } \\
\hline & $\mathrm{A} 1$ & $\mathrm{~A} 2$ & $\mathrm{~A} 3$ & B1 & B2 & B3 & $\mathrm{C} 1$ & $\mathrm{C}_{2}$ & $\mathrm{C} 3$ & \\
\hline Factor1 & 11 & 7 & 2 & 13 & 6 & 1 & 11 & 7 & 2 & $\mathrm{~A} 1 \mathrm{~B} 1 \mathrm{C} 1$ \\
\hline Factor2 & 15 & 3 & 2 & 13 & 7 & 0 & 10 & 8 & 2 & $\mathrm{~A} 1 \mathrm{~B} 1 \mathrm{C} 1$ \\
\hline Factor3 & 8 & 11 & 1 & 5 & 14 & 1 & 7 & 10 & 3 & $\mathrm{~A} 2 \mathrm{~B} 2 \mathrm{C} 2$ \\
\hline Factor 4 & 13 & 4 & 3 & 8 & 10 & 2 & 8 & 10 & 2 & $\mathrm{~A} 1 \mathrm{~B} 2 \mathrm{C} 2$ \\
\hline Factor5 & 14 & 6 & 0 & 15 & 4 & 1 & 12 & 7 & 1 & $\mathrm{~A} 1 \mathrm{~B} 1 \mathrm{C} 1$ \\
\hline Factor6 & 10 & 8 & 2 & 13 & 5 & 2 & 9 & 6 & 5 & $\mathrm{~A} 1 \mathrm{~B} 1 \mathrm{C} 1$ \\
\hline Factor7 & 16 & 3 & 1 & 11 & 9 & 0 & 9 & 11 & 0 & $\mathrm{~A} 1 \mathrm{~B} 1 \mathrm{C} 2$ \\
\hline Factor8 & 8 & 10 & 2 & 6 & 11 & 3 & 3 & 13 & 4 & $\mathrm{~A} 2 \mathrm{~B} 2 \mathrm{C} 2$ \\
\hline Factor 9 & 3 & 12 & 5 & 3 & 8 & 9 & 3 & 6 & 11 & $\mathrm{~A} 2 \mathrm{~B} 3 \mathrm{C} 3$ \\
\hline Factor 10 & 4 & 13 & 3 & 3 & 10 & 7 & 3 & 8 & 9 & $\mathrm{~A} 2 \mathrm{~B} 2 \mathrm{C} 3$ \\
\hline Factor11 & 10 & 8 & 2 & 10 & 8 & 2 & 9 & 6 & 5 & A1B1C1 \\
\hline
\end{tabular}

We emphasize that the various answers given by professionals, considering they have experienced project managers, were related to the fact that they have different professional backgrounds. Thereby, the characterization of a particular factor was based on answers given by most professionals.

Thus, the decision groups were defined as follows. Group I: The influencing factors that will be selected as the most important ones that project managers should take into account when allocating tasks to remote teams (preferable factors).
Group II: The influencing factors that should be less considered by project managers when they need to allocate tasks to remote teams (not preferable factors).

\section{The ORCLASS Method Application}

The ORCLASS method application was aided by the ORCLASSWEB tool, which was divided into four steps: Criteria and criteria value definition; Alternatives definition; Construction of the classification rule; and Results Generation.

We introduced the problem's criteria into the ORCLASSWEB tool. In this step, we specified the criteria's names and their possible values. The tool allowed us to insert all the necessary criteria. Next, we introduced the problem's alternatives into the ORCLASSWEB tool. The tool allowed us to inform the alternatives' names, and their representations in criteria values, according to the criteria defined in the previous step (and in the column "final vector" in Table 2).

The ORCLASSWEB tool also supported the construction of the classification rule. The tool calculates which question would be the next one that the decision maker is supposed to answer according to the ORCLASS method's rules for the selection of the most significant alternative. In this step, we had the support of an experienced project manager to answer the questions to classify the alternatives. The classification rule was completed based on the decision-maker choices. In the end, the tool processed the full classification of the alternatives.

As result of applying the ORCLASSWEB tool, we got the following factors to compose the Group I (the preferable factors): Factor1 - Technical expertise, Factor2 - Expertise in business, Factor3 - Project manager maturity, Factor4 Proximity to client, Factor5 - Low turnover rate, Factor6 Availability, Factor7 - Site maturity, Factor11 - Willingness at site, and Factor8 - Personal trust. They are the most important ones that project managers should consider when allocating tasks in projects of distributed development of software, according to the ORCLASS method. In the Group II, which was composed of the least preferable factors, we got the following factors: Factor9 - Time zone and Factor10 - Cultural similarities.

\section{E. The ZAPROS-III-i Method Application}

After determining the preferred factors using the OSCLASS method, we moved on to the stage of ordering. At this stage, we applied the ZAPROS III-i method to put in order the preferable factors, such that it is possible to establish a ranking of preferred factors. In this step, the least preferable factors were discarded, thereby reducing our workspace.

To facilitate the decision-making process and perform it consistently, we used the ARANAÚ tool, presented in [35, 42 and 43]. The tool, which was implemented in Java platform, was first developed in [36] to support ZAPROS III method. In this work, we used the updated version to ZAPROS III-i method. The use of ZAPROS III-i method in the ARANAÚ tool requires four steps, as follows: Criteria and criteria value definition; Preferences Elicitation; Alternatives Definition; and Results Generation.

First of all, we introduced the criteria presented in the problem into the ARANAÚ tool. Next, the decision-maker 
decides the preferences. The interface for elicitation of preferences presents questionings that can be easily answered by the decision-maker to obtain the scale of preferences. The process occurs in two stages: elicitation of preferences for quality variation of the same criteria and elicitation of preferences between pairs of criteria. The questions provided require a comparison considering the two reference situations [35]. Once the scale of preferences is structured, the next step is to define the problem's alternatives. The alternatives to our problem are the preferable factors integrating of Group I.

\section{RESULTS}

After introducing all the data and answering the necessary questions, the decision maker is presented with the result in a table containing the alternatives and their criteria evaluations, formal index of quality and rank, as exposed in Table 3. Note that there are five alternatives (factors) that are in the same ranking position (first position), and their FIQ's values are equals to zero. This occurs because all of them got the best evaluation according to the survey filled out by the professionals (A1, B1, C1), which is the best possible evaluation.

TABLE 3. THE FINAL RANKING OF ALTERNATIVES
\begin{tabular}{|c|c|c|c|}
\hline Rank & Alternative & Representation & FIQ \\
\hline 1 & Factor1 - Technical expertise & A1B1C1 & 0 \\
\hline 1 & Factor2 - Expertise in business & A1B1C1 & 0 \\
\hline 1 & Factor5 - Low turnover rate & A1B1C1 & 0 \\
\hline 1 & Factor6 - Availability & A1B1C1 & 0 \\
\hline 1 & Factor11 - Willingness at site & A1B1C1 & 0 \\
\hline 2 & Factor7 - Site maturity & A1B1C2 & 6 \\
\hline 3 & Factor4 - Proximity to client & A1B2C2 & 10 \\
\hline 4 & Factor3 - Project manager maturity & A2B2C 2 & 11 \\
\hline 5 & Factor8 - Personal Trust & A2B2C2 & 11 \\
\hline
\end{tabular}

A graph showing the dominance relations between the alternatives is also generated by the ARANAÚ tool and is exposed to provide a more detailed analysis of the problem's resolution. This graph can be seen in Fig. 2 .

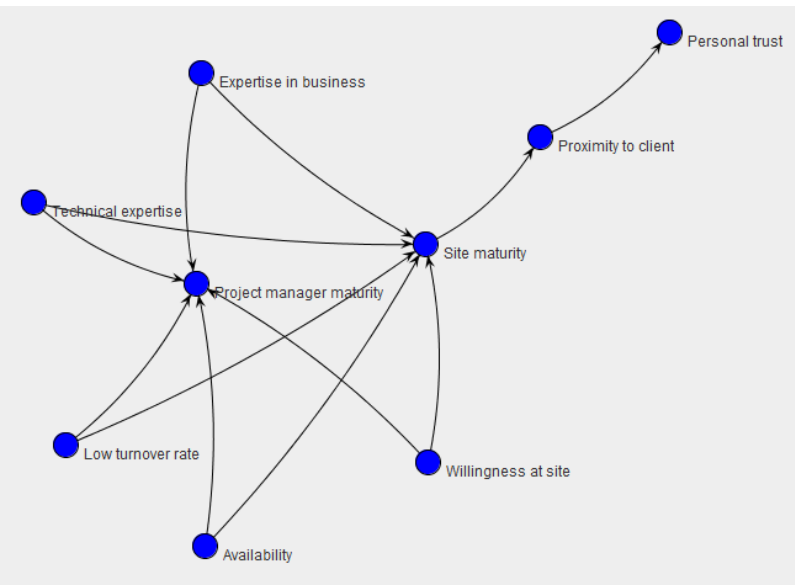

Fig. 2. The graph showing the dominance relations between the alternatives

\section{CONCLUSION AND FUTURE WORKS}

For large software development projects, working with distributed teams has been an alternative increasingly present in large companies. However, the distribution brings many challenges, particularly concerning the allocation of tasks among remote teams, since there are many factors that project managers should take into consideration. Typically, this multicriteria decision-making problem involves subjective aspects. The verbal decision analysis methods support decision-making process through multi-criteria qualitative analysis.

The main contribution of this work was to apply a hybrid methodology based on ORCLASS and ZAPROS III-I methods to select and rank order the most important factors that project managers should consider when allocating tasks among distributed teams. Two tools, ORCLASSWEB, and ARANAÚ, supported this work allowing the performance of the tasks in a fast and practical way. Previously, we conducted interviews and applied questionnaires to a group of project management experts so that we could identify the factors, the criteria and the criteria values to use in the methods.

As future work, we intend to combine this hybrid methodology to other decision support methods so that we can compare the results of them. Also, we intend to develop case studies with real life situations to verify the methodology. Finally, we propose to apply VDA methods to help choosing the team that should be assigned a specific task, based on the task characteristics and teams profiles.

\section{ACKNOWLEDGMENT}

The first author is thankful for the support given by the "Coordination for the Improvement of Higher Level-or Education- Personnel" (CAPES) and 7 de Setembro College. The second author is grateful to National Counsel of Technological and Scientific Development (CNPq) via Grants \#305844/2011-3. The authors would like to thank The Edson Queiroz Foundation/University of Fortaleza for all the support.

\section{REFERENCES}

[1] Almeida L.H., Albuquerque, A.B, Pinheiro, P.R., "A Multi-criteria Model for Planning and Fine-Tuning Distributed Scrum Projects", In: Proceedings of the 6th IEEE International Conference on Global Software Engineering, 2011.

[2] Almeida L.H., Albuquerque, A.B, Pinheiro, P.R., "Applying MultiCriteria Decision Analysis to Global Software Development with Scrum Project Planning", Lecture Notes in Computer Science, v. 6954, p. 311320, 2011.

[3] Babar, M. A. and Zahedi, M., "Global Software Development: A Review of the State-Of-The-Art (2007 - 2011)", IT University Technical Report Series. IT University of Copenha-gen, 2012.

[4] Bana e Costa, C.A., Sanchez-Lopez, R., Vansnick, J.C., De Corte, J.M., "Introducción a MACBETH", In: Leyva López, J.C. (ed.). Análisis Multicriterio para la Toma de Decisiones: Métodos y Aplicaciones, Plaza y Valdés, México (233-241), 2011.

[5] Castro, A.K.A., Pinheiro, P.R., Pinheiro, M.C.D., "Applying a Decision Making Model in the Early Diagnosis of Alzheimer's Disease”, Rough Sets and Knowledge Technology, Lecture Notes in Computer Science, v.4481, p.149-156, 2007.

[6] Castro, A.K.A., Pinheiro, P.R., Pinheiro, M.C.D., "A Multicriteria Model Applied in the Diagnosis of Alzheimer's Disease", Rough Sets and Knowledge Technology, Lecture Notes in Computer Science, v.5009, p.612-619, 2008.

[7] Castro, A.K.A., Pinheiro, P.R., Pinheiro, M.C.D., Tamanini, I., “Applied Hybrid Model in the Neuropsychological Diagnosis of the Alzheimer's Disease: A Decision Making Study Case", International Journal of Social and Humanistic Computing (IJSHC), v.1, n.3, p.331-345, 2010. DOI:10.1504/IJSHC.2010.032692.

[8] Evangelou, C., Karacapilidis, N. and Khaled, O.A., "Interweaving knowledge management, argumentation and decision making in a collaborative setting: the KAD ontology model', International Journal of Knowledge and Learning 1, 1/2, 130-145, 2005. 
[9] Galviña, Z. and Šmite, D., "Software Development Processes in Globally Distributed Environment", In: Scientific Papers, University Of Latvia, Vol. 770, Computer Science and Information Technologies, 2011.

[10] Gomes, L.F.A.M., Moshkovich, H., Torres, A., "Marketing decisions in small businesses: how verbal decision analysis can help", International Journal Management and Decision Making 11, 1, 19-36, 2010.

[11] Lamersdorf, A. and Münch, J., "A multi-criteria distribution model for global software development projects", The Brazilian Computer Society, 2010.

[12] Lamersdorf, A., Münch, J. and Rombach, D., "Towards a Multi-Criteria Development Distribution Model: An Analysis of Existing Task Distribution Approaches", In: IEEE International Conference on Global Software Engineering, ICGSE 2008, 2008.

[13] Lamersdorf, A., Münch, J. and Rombach, D., "A Survey on the State of the Practice in Distributed Software Development: Criteria for Task Allocation", In Fourth IEEE International Conference on Global Software Engineering, ICGSE 2009, 2009.

[14] Larichev, O.I., "Ranking multicriteria alternatives: The Method ZAPROS III", European Journal of Operational Research, v. 131, n. 3, p. $550-558,2001$.

[15] Larichev, O.I., Brown, R., "Numerical and verbal decision analysis: comparison on practical cases", Journal of Multicriteria Decision Analysis 9, 6, 263-273, 2000.

[16] Larichev, O., "Method ZAPROS for Multicriteria Alternatives Ranking and the Problem of Incomparability", Informatica, v. 12, n. 1, p. 89-100, 2001.

[17] Larichev, O.I. and Moshkovich, H.M., "Verbal Decision Analysis for Unstructured Problems", Boston: Kluwer Academic Publishers, 1997.

[18] Machado, T.C.S., Menezes, A.C., Pinheiro, L.F.R., Tamanini, I., Pinheiro, P.R., "The selection of prototypes for educational tools: an applicability in verbal decision analysis", IEEE International Joint Conferences on Computer, Information, and Systems Sciences, and Engineering, 2010.

[19] Machado, T.C.S., Menezes, A.C., Pinheiro, L.F.R., Tamanini, I., Pinheiro, P.R., "Applying verbal decision analysis in selecting prototypes for educational tools", IEEE International Conference on Intelligent Computing and Intelligent Systems, Xiamen, China, pp. 531$535,2010$.

[20] Machado, T.C.S., Pinheiro, P.R., Albuquerque, A.B., de Lima, M.M.L., "Applying verbal decision analysis in selecting specific practices of CMMI", Lecture Notes in Computer Science 7414, 215-221, 2012.

[21] Machado, T. C. S., "Towards Aided by Multicriteria Support Methods and Software Development: A Hybrid Model of Verbal Decision Analysis for Selecting Approaches of Project Management", Master Thesis. Master Program in Applied Computer Sciences, University of Fortaleza, 2012

[22] Machado, T. C. S., Pinheiro, P. R., Tamanini, I., "OrclassWeb: A Tool Based on the Classification Methodology ORCLASS from Verbal Decision Analysis Framework", Mathematical Problems in Engineering, v. 2014, Article ID 238168, 11 pages, DOI: 10.1155/2014/238168, 2014.

[23] Machado, T.C.S., Pinheiro, P.R., Tamanini, I., "Project Management Aided by Verbal Decision Analysis Approaches: A Case Study for the Selection of the Best SCRUM Practices", International Transactions in Operational Research, v. 22, n. 2, p.287-312, DOI: 10.1111/itor.12078, 2014.

[24] Marques, A. B., Rodrigues, R., and Conte, T., "Systematic Literature Reviews in Distributed Software Development: A Tertiary Study", In: IEEE International Conference on Global Software Engineering, ICGSE 2012: 134-143, 2012.

[25] Marques, A. B., Rodrigues, R., Prikladnicki R. and Conte, T., “Alocação de Tarefas em Projetos de Desenvolvimento Distribuído de Software: Análise das Soluções Existentes", II Congresso Brasileiro de Software, V WDDS - Workshop de Desenvolvimento Distribuído de Software, São Paulo, 2011.

[26] Mendes, M.S., Carvalho, A.L., Furtado, E., Pinheiro, P.R., "A coevolutionary interaction design of digital TV applications based on verbal decision analysis of user experiences", International Journal of Digital Culture and Electronic Tourism 1, 312-324, 2009.

[27] Miller, A., "Distributed Agile Development at Microsoft patterns \& practices", Microsoft patterns \& practices, 2008.

[28] Moshkovich, H. M., Mechitov, A., "Verbal Decision Analysis: Foundations and Trends", Advances in Decision Sciences, v. 2013, Article ID 697072, 9 pages, DOI: 10.1155/2013/697072, 2013.

[29] Moshkovich, H. M., Mechitov, A. and Olson, D., "Ordinal Judgments in Multiattribute Decision Analysis", European Journal of Operational Research, v. 137, n. 3, p. 625-641, 2002.

[30] Pinheiro, P.R., Machado, T. C. S., Tamanini, I., "Verbal Decision Analysis Applied on the Choice of Educational Tools Prototypes: A Study Case Aiming at Making Computer Engineering Education Broadly Accessible", International Journal of Engineering Education, v. 30, p. 585-595, 2014.

[31] Ruano-Mayoral, M., Casado-Lumbreras, C., Garbarino-Alberti, H. and Misra, S., "Methodological framework for the allocation of work packages in global software development", In Journal of Software: Evolution and Process, J. Softw. Evol. and Proc., 2013.

[32] Simão Filho, M, Pinheiro, P.R., Albuquerque, A.B., "Task Allocation Approaches in Distributed Agile Software Development: A Quasisystematic Review", In: 4th Computer Science On-line Conference 2015, 2015, Zlín. Proceedings of the 4th Computer Science On-line Conference 2015 (CSOC2015), Vol 3: Software Engineering in Intelligent Systems, 2015. v. 3. p. 243-252, 2015.

[33] Simão Filho, M, Pinheiro, P.R., Albuquerque, A.B., "Task Allocation in Distributed Software Development aided by Verbal Decision Analysis", In: 5th Computer Science On-line Conference 2016 (CSOC2015), Zlín. Proceedings of the 5th Computer Science On-line Conference 2016, 2016, in press.

[34] Tamanini, I., "Hybrid Approaches of Verbal Decision Analysis Methods", Doctor Thesis, Graduate Program in Applied Informatics, University of Fortaleza, 2014.

[35] Tamanini, I., "Improving the ZAPROS Method Considering the Incomparability Cases", Master Thesis, Master Program in Applied Computer Sciences, University of Fortaleza, 2010.

[36] Tamanini, I., "Uma ferramenta Estruturada na Análise Verbal de Decisão Aplicando ZAPROS", Computer Sciences, University of Fortaleza, 2007.

[37] Tamanini, I., Carvalho, A.L., Castro, A.K.A., Pinheiro, P.R., "A novel multicriteria model applied to cashew chestnut industrialization process", Advances in Soft Computing 58, 1, 243-252. 2009.

[38] Tamanini, I., de Castro, A.K.A., Pinheiro, P.R., Pinheiro, M.C.D., "Towards an applied multicriteria model to the diagnosis of Alzheimer's disease: a neuroimaging study case", 2009 IEEE International Conference on Intelligent Computing and Intelligent Systems, Vol. 3, pp. 652-656, 2009.

[39] Tamanini, I., de Castro, A.K.A., Pinheiro, P.R., Pinheiro, M.C.D., "Verbal decision analysis applied on the optimization of Alzheimer's disease diagnosis: a study case based on neuroimaging", Advances in Experimental Medicine and Biology 696, 555-564, 2011.

[40] Tamanini, I., Machado, T.C.S., Mendes, M.S., Carvalho, A.L., Furtado, M.E.S., Pinheiro, P.R., "A model for mobile television applications based on verbal decision analysis", Advances in Computer Innovations in Information Sciences and Engineering 1, 1, 399-404, 2008.

[41] Tamanini, I., Pinheiro, P.R., "Challenging the incomparability problem: an approach methodology based on ZAPROS", Modeling, Computation and Optimization in Information Systems and Management Sciences, Communications in Computer and Information Science, 14, 338-347, 2008.

[42] Tamanini, I.; Pinheiro, P. R., "Applying a New Approach Methodology with ZAPROS", In: XL Brazilian Symposium on Operations Research, p. 914-925, 2008.

[43] Tamanini, I.; Pinheiro, P. R. "Reducing Incomparability in Multiciteria Decision Analysis: An Extension of The ZAPROS Methods", Pesquisa Operacional (Print), v. 31, n. 2, p. 251-270, DOI: 10.1590/S010174382011000200004, 2011. 